\title{
HIGH EFFICIENCY WIRELESS ELECTROCHEMICAL ACTUATORS: DESIGN, FABRICATION AND CHARACTERIZATION BY ELECTROCHEMICAL IMPEDANCE SPECTROSCOPY
}

\author{
R. Sheybani and E. Meng \\ University of Southern California, Los Angeles, CA, USA
}

\begin{abstract}
A wirelessly-actuated high efficiency Nafion ${ }^{\circledR}$-coated MEMS electrochemical actuator is presented. For the first time, high flow rates were achieved (up to $141 \mu \mathrm{L} / \mathrm{min}$, $13 \mathrm{~mA}$ ) under wireless operation and high efficiency pumping (up to 97\%) was obtained with $\mathrm{Nafion}^{\mathbb{B}}$-coated electrodes; coating further prevented previously reported current-induced damage to electrodes [1]. Electrochemical impedance spectroscopy (EIS) was used for electrode characterization, electrochemical cleaning, as well as investigation of delamination, electrode polymer coating and surface activation. Parylene and PEEK were investigated as flexible substrate substitutes for soda lime glass. As a result of the combined effect of the rough PEEK surface (increased electrode surface area) and the Nafion ${ }^{\circledR}$ coating, higher efficiency was achieved compared to glass.
\end{abstract}

\section{INTRODUCTION}

Electrochemically driven mechanical pumps feature low power consumption, low heat generation, accurate flow control, and large driving force. These factors, combined with the potential for biocompatible construction and wireless actuation, enable many interesting biological and medical applications [1].

Previously, we reported a microelectrochemical actuator capable of flow rates up to $6.5 \mu \mathrm{L} / \mathrm{min}$ (constant current operation, $1 \mathrm{~mA}$ ) [1]. The electrolysis actuator consisted of interdigitated Pt electrodes on a glass substrate. Efficiency up to $90 \%$ was achieved by increasing electrode surface area by electroplating; however, due to delamination, repeatable and reliable operation was not achieved. Delamination of Pt electrodes on flexible Parylene films was also reported in [3]. Here, we present Nafion ${ }^{\circledR}$ coated and wirelessly-operated actuators that are mechanically robust and exhibit high efficiency actuation for high flow rate in vivo drug delivery applications.

Electrochemical impedance spectroscopy has been used to characterize Pt electrodes and to investigate corrosion, surface activation, and the metal-polymer interface for fuel cell applications [2]. EIS is applied here to characterize $\mathrm{Pt}$ electrodes used as electrolysis actuators. The impedance spectra can be used to calculate equivalent circuit parameters (double layer capacitance, polarization resistance, and electrolyte resistance) that provide valuable information about the electrodes. For instance, the double layer capacitance is directly proportional to the effective surface area. EIS could also be used to estimate the thickness of the Nafion ${ }^{\circledR}$ coating which acts as a dielectric in the double layer capacitance.

\section{DESIGN}

Constant current applied to an electrode pair results in water electrolysis and subsequently, a pressure increase that can be harnessed for actuation. For example, the generated pressure can be used to deflect a flexible membrane which acts on the fluid to be pumped or directly pump the electrolyzed fluid through an opening in a rigid chamber (Fig. 1).

(a)

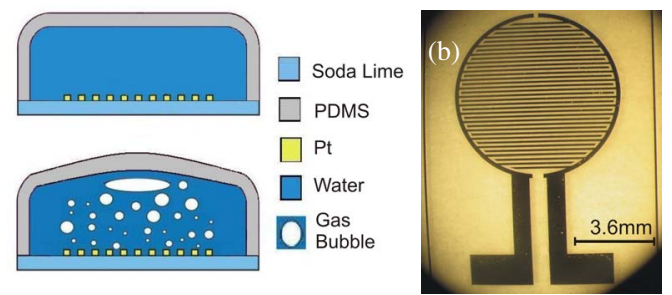

Figure 1: Electrochemical actuator: (a) operation concept and (b) fabricated interdigitated electrodes.

In our previous electrolysis actuator [1], generated gas bubbles could occlude the active electrode surface and prevent contact with the electrolyte (water) which reduces pumping efficiency. Thus, Nafion ${ }^{\circledR}$ coating of electrodes is introduced here to prevent bubble occlusion of the electrode and improve efficiency without interfering with electrolysis operation. The polymer electrolyte coating possesses high gas solubility allowing rapid diffusion of bubbles away from the catalyst surface and leads to a $20 \%$ increase in current density [4].

It is important to note that the effective surface area of Nafion ${ }^{\circledR}$ coated Pt electrodes is reduced compared to that of the native, uncoated Pt electrode ( $86 \%$ of original area). The smaller value suggests that part of the Pt surface is blocked by the electrochemically inactive hydrophobic fluorocarbon backbone of Nafion $^{\mathbb{R}}$ [5]. Optimal performance was reported for coatings composed of less than 9 wt. \% Nafion ${ }^{\circledR}$ [6].

\section{FABRICATION}

Interdigitated $\mathrm{Pt}$ electrodes were fabricated on soda lime substrates by liftoff [1]. A dual-layer photoresist process was used to create an undercut sidewall profile to facilitate metal liftoff. First, AZ1518 photoresist (AZ Electronic Materials, Branchburg, NJ) was spun at $4 \mathrm{krpm}$ followed by global exposure. Then, AZ4400 photoresist (AZ Electronic Materials, Branchburg, NJ) was applied at 4 $\mathrm{krpm}$ and patterned. Following a short descum in oxygen plasma, a Ti/Pt film (300 $\AA / 2000 \AA)$ was e-beam evaporated and then liftoff was performed. 
Flexible electrodes were fabricated using the same liftoff method. For electrodes on thin film Parylene C (Specialty Coating Systems, Indianapolis, IN) membranes ( $5 \mu \mathrm{m}$ thick), the Parylene was first deposited on clean silicon substrates. Then electrodes were patterned. Following removal from the supporting $\mathrm{Si}$ substrate by careful peeling, electrodes were mounted on a flexible polyetheretherketone (PEEK) substrate using adhesive, as reported in [3]. For electrodes on PEEK, 0.020" thick PEEK $^{\text {TM }}$ Film (CS Hyde Co., IL, USA) was first cleaned and then electrodes were patterned.

Prior to Nafion ${ }^{\circledR}$ coating, the electrodes were potentiostatically cleaned at $\pm 0.5 \mathrm{~V}$ (Gamry Reference 600 Potentiostat, Warminster, PA) in 1X phosphate buffered saline. Nafion ${ }^{\circledR}$ (Dupont DE521 Solution, Ion Power, INC, New Castle, DE) was applied to the electrodes by dip coating 2 times which produces a $1 \mu \mathrm{m}$ thick coating.

\section{EXPERIMENTS AND RESULTS}

\section{Polymer Coating on Glass Electrodes}

EIS (Gamry Reference 600 Potentiostat) was performed in $1 \mathrm{X}$ phosphate buffered saline on uncoated and Nafion ${ }^{\circledR}$ coated soda lime electrodes (Fig. 2). The Nafion ${ }^{\circledR}$ dielectric film contributes to the double layer capacitance as represented in the equivalent circuit of the electrodeelectrolyte interface $\left(C_{d l}=\right.$ double layer capacitance, $R_{p}=$ polarization resistance, $R_{s}=$ electrolyte resistance). The EIS data demonstrates that the double layer capacitance decreases with increasing coating thickness, suggesting a decrease in active surface area and blocking of some activation sites on the electrode by the hydrophobic backbone of Nafion $^{(}$[5]. Therefore, the usable coating thickness is limited. However, dip coating once, twice and 3 times did not increase the thickness enough for this effect to be observed (data not shown).

\section{Actuator Characterization}

The flow rate was determined by clamping the actuator in a test fixture filled with water (Fig. 3). The accumulated pumped water was weighed over 5 minutes of constant current application.

High flow rates were achieved up to $141 \pm 0.4 \mu \mathrm{L} / \mathrm{min}$ and $80.25 \pm 1.3 \mu \mathrm{L} / \mathrm{min}$ at $13 \mathrm{~mA}$ for coated and uncoated electrodes, respectively (Fig. 4). The results clearly show the increase in flow rate at all current values tested for the Nafion ${ }^{\circledR}$ coated electrodes. Also, the solid polymer electrolyte acts as a barrier between the gas bubbles and the active electrode surface which increases the sites for gas bubble formation and results in greater linearity in the flow rate vs. current relationship.

Flow rate results were compared for electrodes dipped once, twice and three times in Nafion ${ }^{\circledR}$ (data not shown). While the coating thicknesses examined did not exhibit the significantly different flow rates, a single coating resulted in loss of coating integrity after repeated operation at high current. Sufficient robustness was achieved for electrodes that were dip coated twice.

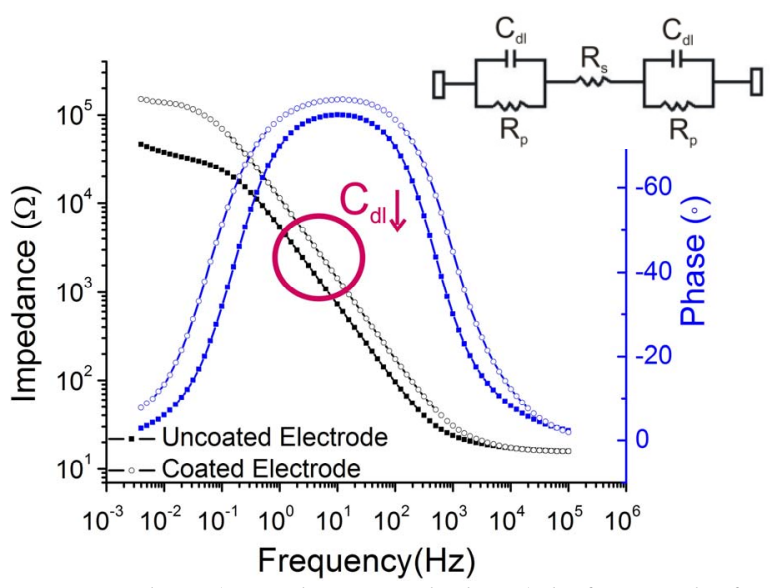

Figure 2: EIS data (impedance and phase) before and after Nafion $^{\circledR}$ coating: drop in double layer capacitance (slope of plot) suggests decrease in surface area (coating thickness = 10460 A). Inset: schematic diagram of equivalent electrochemical circuit.

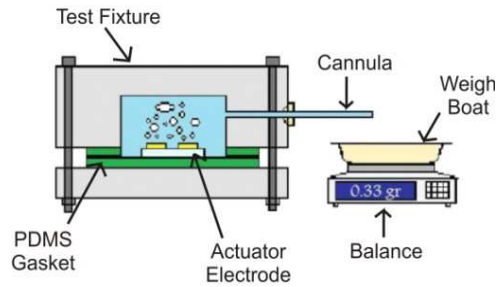

Figure 3: Flow rate measurement test setup.

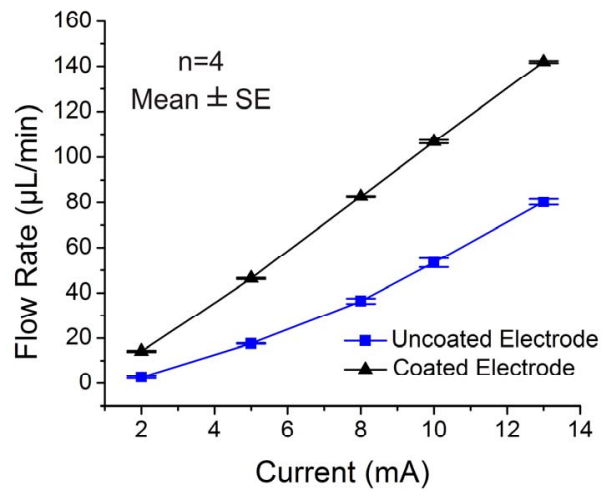

Figure 4: Current controlled flow delivery results with and without Nafion ${ }^{\circledR}$-coating for electrodes on glass substrate.

The efficiency $(\eta)$ associated with the electrolysis reaction is expressed as:

$$
\eta=\frac{V_{\text {experimental }}}{V_{\text {theoretical }}}
$$

where $V_{\text {experimental }}$ is the total volume of the generated hydrogen and oxygen gases and $V_{\text {theoretical }}$ is the theoretical volume of the generated gas bubbles [7]. $V_{\text {theoretical }}$ is calculated from: 


$$
V_{\text {theoretical }}=q_{\text {theoretical }} t=\left(\frac{3}{4} \frac{i}{F} V_{m}\right) t
$$

where $q_{\text {theoretical }}$ is the theoretical gas generation rate (in $\mathrm{m}^{3} / \mathrm{s}$ ), $t$ is duration (in $\mathrm{sec}$ ) over which the current is applied, $i$ is current (in A), $F$ is Faraday's constant $\left(96.49 \times 10^{3}\right.$ $\mathrm{C} / \mathrm{mol}$ ), and $V_{m}$ is the molar gas volume at $25^{\circ} \mathrm{C}$ and atmospheric pressure $\left(24.7 \times 10^{-3} \mathrm{~m}^{3} / \mathrm{mol}\right)$. Efficiency increased with current, reaching $94 \%$ for Nafion ${ }^{\circledR}$-coated electrodes compared to $53 \%$ for uncoated (13mA) (Fig. 5).

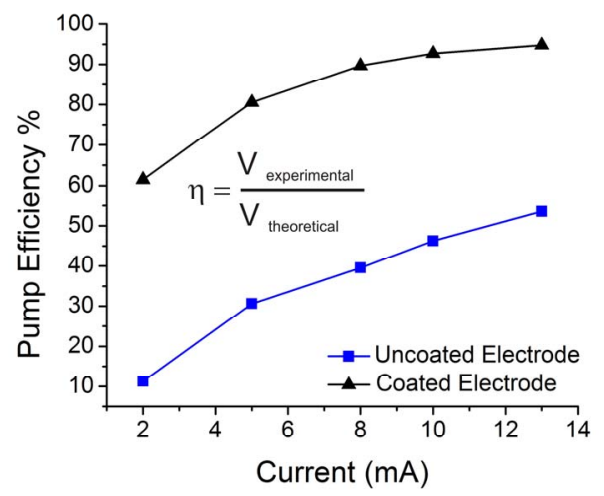

Figure 5: Pump efficiency with and without Nafion ${ }^{\circledR}$-coating for glass substrate.

Flow rate dependence on actuator orientation was investigated with and without Nafion ${ }^{\circledR}$ during constant $10 \mathrm{~mA}$ current application by changing the angle of an actuator clamped in a test fixture (Fig. 6). The Nafion ${ }^{\circledR}$ coating results in a stable flow rate regardless of actuator orientation; the effect is most pronounced at $180^{\circ}$ orientation. This is likely due to the prevention of gas bubble occlusion of the electrode surface.

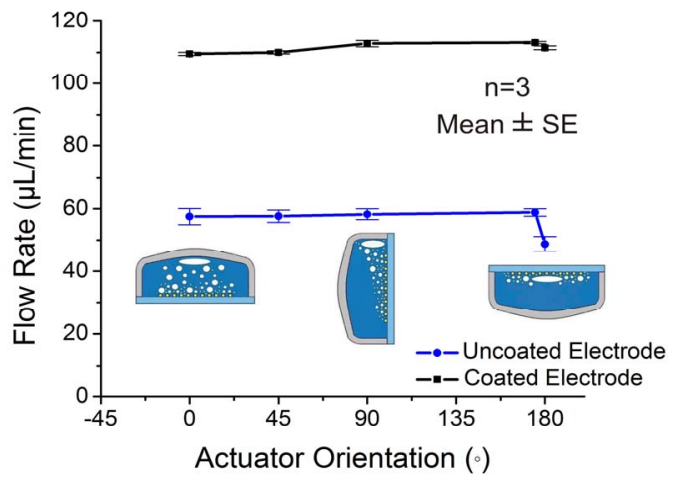

Figure 6: Flow rate vs. angular orientation for coated and uncoated electrodes operated at $10 \mathrm{~mA}$.

\section{Investigation of Delamination of and Electrodeposition on Uncoated Electrodes on Flexible Substrates}

EIS was performed in $1 \mathrm{X}$ phosphate buffered saline and results showed noticeable shifts in the impedance curves following current application on uncoated electrodes fabricated on the flexible Parylene and PEEK substrates. For
Parylene electrodes, a decrease in solution resistance was observed which correlated to electrode delamination verified by visual inspection (Fig. 7). For PEEK electrodes, the double layer capacitance increased which correlated with increased surface area from the rough substrate and the presence of an unknown electrodeposited material following current application (Fig. 8). Electrodeposition was more pronounced on the cathode. The nature of this electrodeposited layer is being further investigated.



Figure 7: EIS results for electrodes on Parylene before and after current application (5mA). Inset: photo of device after current application showing delamination of electrode elements.

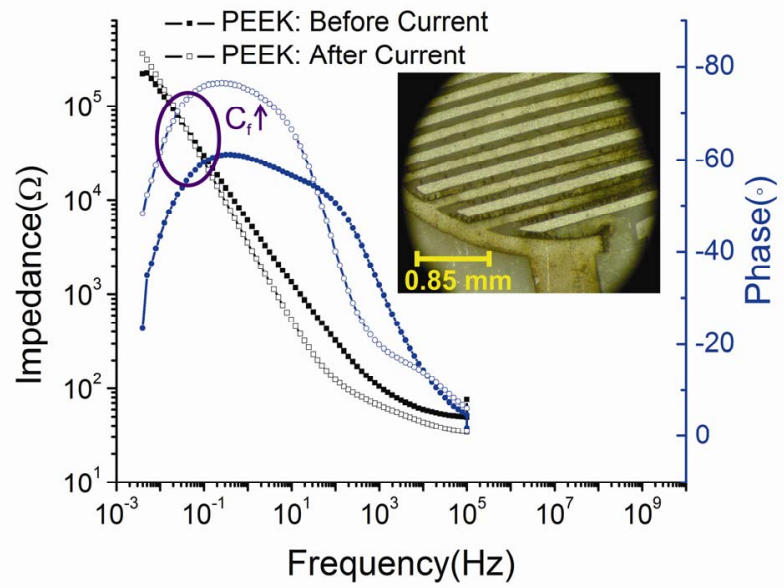

Figure 8: EIS results for electrodes on PEEK before and after current application (5mA). Inset: photo of device after current application showing electrodeposition (black spots).

\section{Polymer Coating on Flexible Electrodes}

Parylene electrodes were coated with $1 \mu \mathrm{m}$ of Nafion ${ }^{\circledR}$ and operated over a range of currents (results not shown). While the coating appeared to delay delamination, it did not prevent it at sufficiently high currents $(>5 \mathrm{~mA})$. Therefore, we conclude that Parylene may not be a suitable material for our application without further treatment to improve the adhesion of Pt. The PEEK electrodes however, once coated 
with Nafion ${ }^{\circledR}$, showed no signs of the electrodeposited material present in the uncoated electrodes following current application. Moreover, as a result of the combined effect of the rough PEEK surface (increased electrode surface area) and the coating, higher efficiency of up to $97 \%$ (13mA) was achieved compared to electrodes on soda lime glass (Fig. 9).

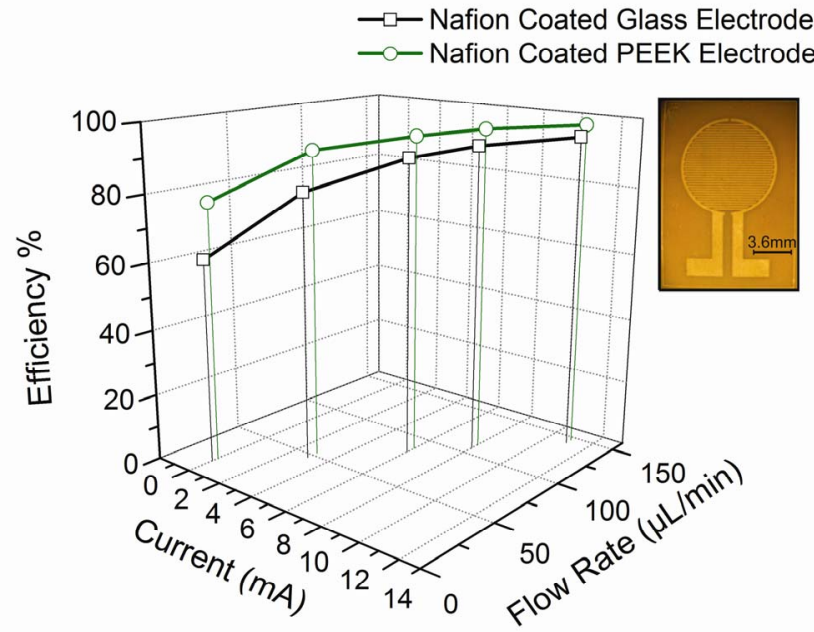

Figure 9: Comparison of Nafion ${ }^{\circledR}$-coated glass and PEEK electrodes: current controlled flow delivery. Inset: photo of PEEK electrode after current application. Coating protects electrodes from delamination and electrodeposition.

\section{Wireless Performance}

A class D wireless system was designed and implemented to provide constant current operation between 1mA-10mA (Fig. 10). Uncoated and coated electrodes were operated wirelessly with the constant current output set to $10 \mathrm{~mA}$. Flow rates were slightly larger than those for wired constant current operation due to noise in the current output of the wireless system (Fig. 11).

\section{CONCLUSION}

We demonstrated high efficiency actuators compatible with wireless operation, capable of delivering flow rates of up to $141 \mu \mathrm{L} / \mathrm{min}$ at $13 \mathrm{~mA}$. Coated and rough electrodes significantly improved efficiency, enabling future application of low-power actuators in wireless drug delivery pumps. Flexible substrate actuators further enable in vivo and other diverse applications.

Future work includes integration of actuators with a into a drug delivery pump for in vivo drug addiction studies in freely behaving mice.

\section{ACKNOWLEDGEMENTS}

This work was funded in part by a Wallace H. Coulter Foundation Early Career Translational Research Award and NIH/NIDA under award number R21DA026970. The authors would like to thank Dr. F. Mansfeld, Dr. A. K. Manohar, Dr. D. Holschneider, Dr. J.M. Maarek, and the members of the USC Biomedical Microsystems Laboratory for their assistance with this project.
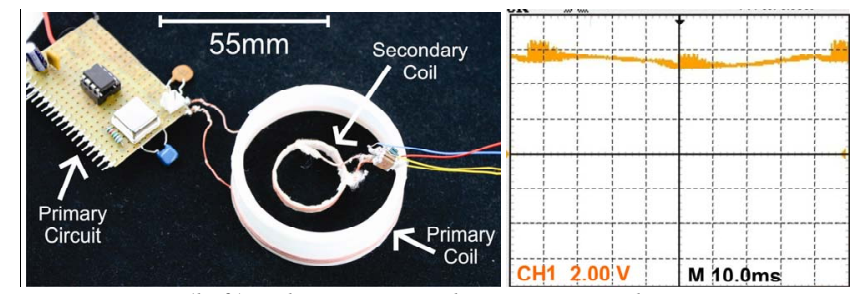

Figure 10: (left) Class D wireless system showing primary and secondary circuits, (right) voltage output trace.

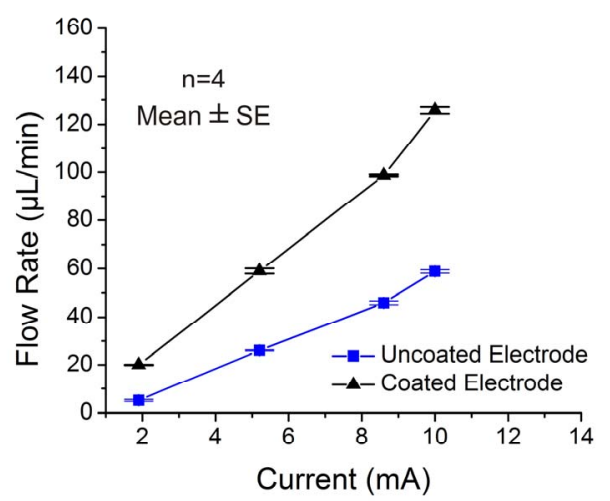

Figure 11: Wireless flow delivery for coated and uncoated electrodes.

\section{REFERENCES}

[1] P.Y. Li, R. Sheybani, C. Gutierrez, J.T.W. Kuo, and E. Meng, "A Parylene Bellows Electrochemical Actuator", in J. Microelectromech. Syst., 19, 2010, pp. 215-228.

[2] A. Parthasarathy, B. Dave, S. Srinivasan, and A.J. Appleby, "The Platnium Microelecrode/Nafion ${ }^{\circledR}$ Interface: An Electrochemical Impedance Spectroscopic Analysis of Oxygen Reduction Kinetics and Nafion ${ }^{\circledR}$ Characteristics", J. Electrochem. Soc., 139, 1992, pp. 1634-1641.

[3] H. Gensler, R. Sheybani, P.Y. Li, R. Lo, S. Zhu, K. Yong, I. Roy, P. N. Prasad, R. Masood, U.K. Sinha, E. Meng, "Implantable MEMS drug delivery device for cancer radiation reduction," MEMS 2010, pp.23-26, 2428 Jan. 2010.

[4] Z. Ogumi, T. Kuroe, Z.-i. Takehara, "Gas Permeation in SPE Method: Oxygen and Hydrogen Permeation Through Nafion ${ }^{\circledR}$, , J. Electrochem. Soc., 132, 1985, p2601.

[5] J. Maruyama, M. Inaba, K. Katakura, Z. Ogumi, and Z. Takehara, "Influence of Nafion ${ }^{\circledR}$ film on the kinetics of anodic hydrogen oxidation", J. Electroanal. Chem., 447, 1998, pp. 201-209.

[6] T. Ioroi, K. Yasuda, Z. Siroma, N. Fujiwara, and Y. Miyazaki, "Thin film electrocatalyst layer for unitized regenerative polymer electrolyte fuel cells", Journal of Power Sources 112, 2002, pp 583-587.

[7] D. E. Lee, S. A. Soper, and W. Wang, "Fabrication and mathematical analysis of an electrochemical microactuator (ECM) using electrodes coated with platinum nano-particles", Microsystem Technologies, 16, 2010, pp. 381-390. 